\title{
LA DIRECCIÓN ARTÍSTICA EN EL FLAMENCO. EXPERIENCIAS DESDE MI VENTANA
}

\author{
Ángel Rojas \\ Director artístico \\ Fecha de recepción: 04/12/2020 \\ Fecha de aceptación: 25/10/2021
}

\section{Resumen}

El artículo propone un recorrido por el proceso de creación del espectáculo Desde mi ventana, protagonizado por el bailaor flamenco Farruquito. Propone, en base a distintos momentos (el encargo, el reto, el proceso, la experiencia, la maduración, la obra), una reflexión acerca de cómo la experiencia personal del director se imbrica con las demandas del intérprete para producir un espectáculo final. En virtud de las claves de comprensión y planificación, la exposición de la idea, los procesos comunicativos, la actividad de acompañamiento del artista, el descubrimiento mutuo y la confección del diseño, se propone un orden escénico donde el espacio, la dinámica y los límites interpretativos permiten un acercamiento directo a la obra.

Palabras clave: Flamenco, dirección escénica, coreografía, danza.

\section{ARTISTIC DIRECTION IN FLAMENCO. EXPERIENCES FROM MY WINDOW}

\begin{abstract}
The article proposes a journey through the process of creating the show From my window, starring flamenco dancer Farruquito. Based on different moments (the commission, the challenge, the process, the experience, the maturation, the work) it goes through a reflection on how the director's personal experience is interwoven with the demands of the interpreter to produce a final show. In virtue of the keys to understanding and planning, the exhibition of the idea, the communicative processes, the artist's accompaniment activity, mutual discovery and the making of the design, a scenic order is proposed where space, dynamics and limits interpretive allow a direct approach to the scenic work.
\end{abstract}


Enclaves. Revista de Literatura, Música y Artes Escénicas, n. ${ }^{\circ}$ 1, 2021, pp. 144-155. e-ISSN 2792-7350

Ángel Rojas, «La dirección artística en el flamenco. Experiencias Desde mi ventana»,

Keywords: Flamenco, Artistic direction, Choreography, Dance.

\section{Sumario}

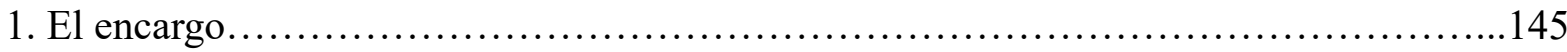

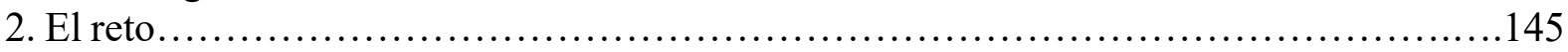

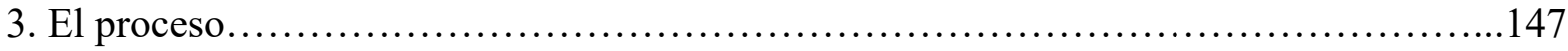

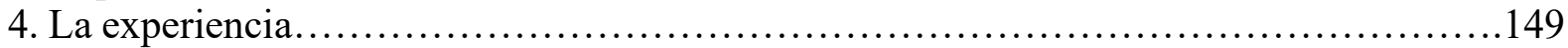

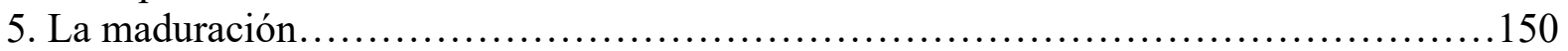

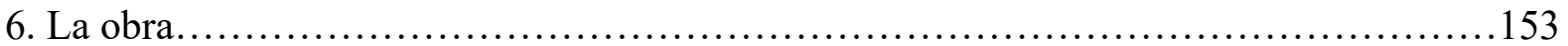

\section{El encargo}

5 de mayo, Candeleda (Ávila).

Suena el teléfono en pleno confinamiento.

-Sí, dígame.

- Quisiera hablar con ***.

-Sí, soy yo.

-Hola, ***. Soy Farruquito, y me gustaría hacerte el encargo de dirigir Desde mi ventana, mi próxima obra para la Bienal de Sevilla...

Desde ese momento, mi cuerpo seguía confinado, pero mi mente comenzaba a volar a los lugares donde nace lo incierto, lo inesperado, el vértigo... Volvía a estar conectado con la creación.

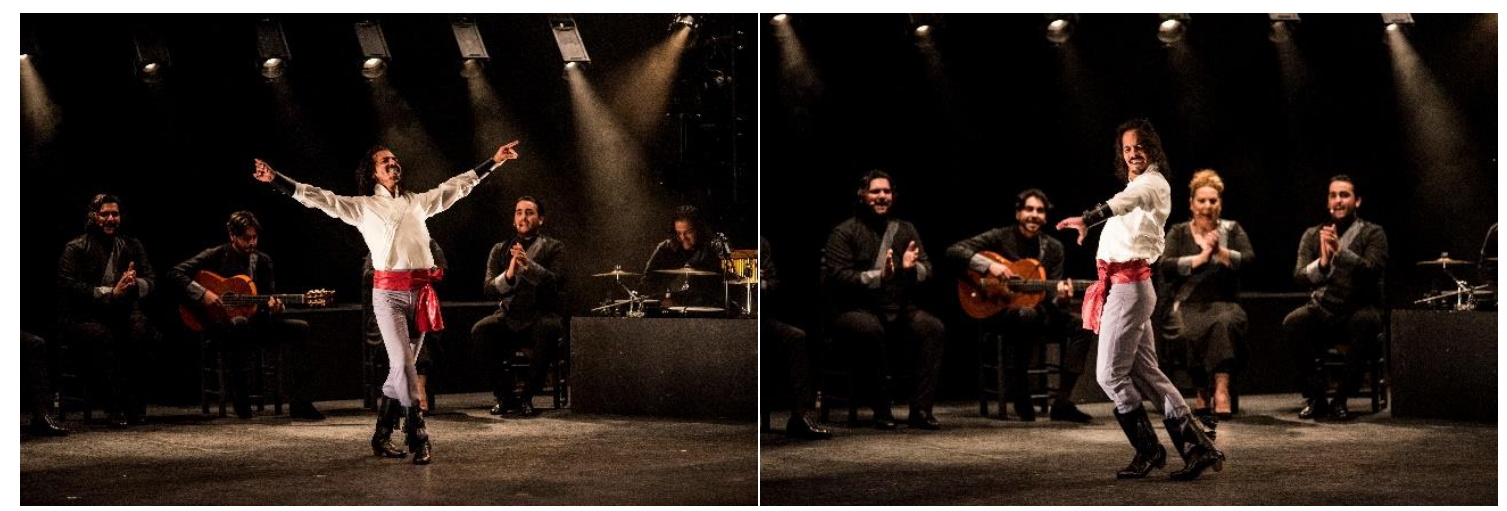

Imagen 1. El baile de Farruquito. Desde mi ventana, Bienal de Flamenco, Sevilla, 2020. Fotografía: Claudia Ruiz Claro.

\section{El reto}

Yo carezco de método aprendido en alguna escuela de dirección para poder dirigir a un intérprete flamenco. En mi caso, necesito conocer cuáles son sus verdades, por muy oscuras y profundas que puedan llegar a ser. Me entrego a la intuición como primer mandamiento para ahondar en la singularidad - a veces llamada «esencia» en el mundo flamenco- de los intérpretes, que poseen el vellocino de oro, pero carecen de herramientas para hacerlo brillar y, claro está, a una vida dedicada al aprendizaje dentro y fuera de los márgenes flamencos, siempre teniendo el arte como motor de vida y creación. 
Enclaves. Revista de Literatura, Música y Artes Escénicas, n. ${ }^{\circ}$ 1, 2021, pp. 144-155. e-ISSN 2792-7350

Ángel Rojas, «La dirección artística en el flamenco. Experiencias Desde mi ventana», https://dx.doi.org/10.12795/enclaves.2021.101.09

En treinta años de carrera artística, he podido habitar infinidad de pieles. La interpretación, la coreografía, la producción, la iluminación... He sentido la gloria y el dolor en mis propias articulaciones, pero no solo las que unen un hueso con otro, sino también las que unen los sentimientos, que hacen al intérprete un ser único en la gloria y vulnerable fuera de ella. Por esa razón, decidí dedicar mi conocimiento a ser más útil para los demás de lo que lo soy para mí mismo. Esa es la verdadera razón por la que soy director.

Cuando tenía 16 años, tuve la fortuna de formar parte del elenco de la compañía del maestro José Granero en la reposición del Ballet Español de Madrid, compañía de su primera etapa en los años 80. Tuvo gran relevancia para la creación de una nueva forma de narrar el baile español en un país que recién estaba despertando de cuarenta años de férrea dictadura franquista; contó entre sus filas con figuras tan importantes como Merche Esmeralda, José Antonio, Goyo Montero o El Güito. El maestro Granero, creador icónico y revolucionario donde los haya, coreografió la que considero la obra más importante de nuestro baile español, Medea, creada para el Ballet Nacional en 1984, con dramaturgia adaptada por el maestro Miguel Narros.

Granero fue quien me enseñó que, cuando diriges a un intérprete de danza, tienes que ser como una flecha que solo puede ir en una dirección. Si, por el contrario, esa flecha cambia y oscila, no se llegará al fondo de lo esencial y todo quedará en un fallido intento. Agarrar por la raíz lo que emana del paso para convertirlo en narrativa sin texto, para que las secuencias coreográficas sean la narrativa en movimiento. He aquí la diferencia entre el teatro de texto y el teatro bailado. Cuando se trata de aplicar las mismas reglas para dirigir al intérprete flamenco es cuando la experiencia se convierte en un choque de trenes.

He vivido, a lo largo de mi carrera, diferentes experiencias muy valiosas con grandes directores de teatro y ópera: con Gerardo Vera en la obra Salomé, de la coreógrafa Carmen Cortés, estrenada en el festival de Mérida en 1996; o con el mítico director de cine Franco Zeffirelli junto a José Carreras, en la ópera Carmen, para la Arena de Verona en 1997. En ambos casos, eran directores para quienes los códigos del movimiento, tanto en el flamenco como en la danza, les eran en general desconocidos, resultando las creaciones interesantes, pero definitivamente irregulares. Por el contrario, cuando el director está asociado al fundamento radical del estilo, se consiguen grandes puntos comunes que hacen que la creación brille y, sobre todo, conecte con el público. Sirvan de ejemplos Torero, en 1993, del maestro Antonio Canales y dirigido por Luis Olmos, o Cachorro, en 1994, del maestro José Antonio, dirigida por Salvador Távora, sin duda, el gran revolucionario y defensor a través de su obra de los valores del pueblo trabajador y que, a lo largo de toda su dilatada carrera, siempre ha sido fiel a esos principios ético-artísticos. Távora dejó a las siguientes generaciones un legado artístico con unos códigos únicos para que podamos seguir ahondando y aprendiendo de ellos.

Aplicando esta conclusión en la escena flamenca, a la hora de dirigir, es clave entender de qué modo hay que mirar y convencer de forma persuasiva al intérprete para que haga lo que necesitas y se sienta identificado con ello. Si no lo consigues, siempre se ha de tener un plan alternativo para que el intérprete no se sienta perdido e inseguro. La responsabilidad del director es proteger la materia más sensible que habita en la plena confianza entre el intérprete y el director. 
Enclaves. Revista de Literatura, Música y Artes Escénicas, n. ${ }^{\circ}$ 1, 2021, pp. 144-155. e-ISSN 2792-7350

Ángel Rojas, «La dirección artística en el flamenco. Experiencias Desde mi ventana», https://dx.doi.org/10.12795/enclaves.2021.i01.09

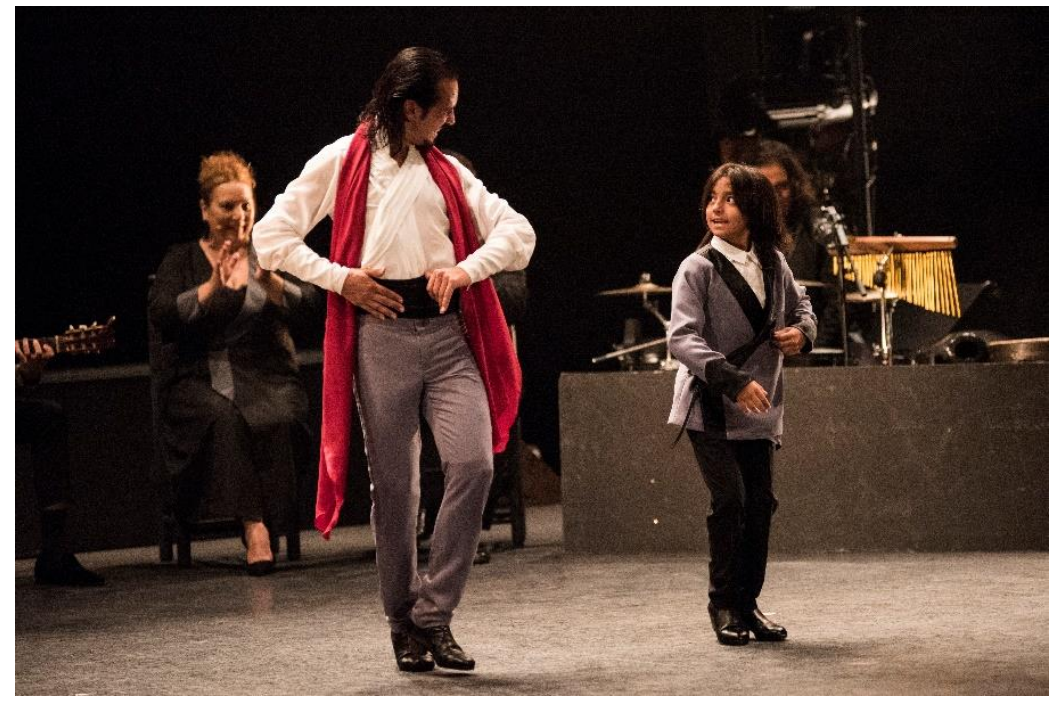

Imagen 2. Farruquito y su hijo, El Moreno, bailando a dos. Desde mi ventana, Bienal de Flamenco, Sevilla, 2020. Fotografía: Claudia Ruiz Claro.

La discreción es una virtud que se hace fundamental cuando diriges dentro de los márgenes flamencos, porque, en mi opinión, el flamenco nace no solo del trabajo constante y del aprendizaje de los maestros, sino que también tiene un componente espontáneo y libre, y está vinculado a las vivencias en comunidad. Si un director quiere que todo eso esté, como se dice en el argot teatral, «a favor de obra», tiene que ser el ratón que habita en la esquina de la sala de ensayo y solo salir cuando el intérprete se siente cómodo para sacar un buen trozo de queso. Es en ese momento cuando la verdad está servida en bandeja y el director se convierte en un flamenco más, que incorpora la narrativa a compás de los pasos de los bailaores y las falsetas de los guitarristas.

«Al buen director no se le siente cuando está, pero todo el mundo le echa a faltar cuando deja de estar». Esto es algo que me enseñó el director escénico de la mítica compañía canadiense Carbone 14, Gilles Maheu, durante el proceso de creación del musical Don Juan, estrenado en Montreal en 2003, donde desarrollé junto a Carlos Rodríguez toda la partitura coreográfica.

Todo proceso creativo es un camino incierto; lo que te funcionó ayer, por razones que no son lógicas, hoy deja de funcionar, y es que la lógica y el arte no son buenas compañeras.

\section{El proceso}

Para afrontar el encargo de dirigir a una de las máximas figuras masculinas del baile flamenco de nuestro tiempo, la primera pregunta que me planteó el viaje fue que no podía dirigir a Farruquito sin antes conocer a Juan Manuel Fernández Montoya. En ese momento, yo era un extraño dentro de un mundo dominado por la tradición, los valores del pueblo gitano y las costumbres arraigadas en una de las sagas más importantes del arte flamenco. Si quería llegar a «ser útil», no podía dejar de adentrarme en todo eso.

Como director en el flamenco, solo se puede ser útil si hablas el mismo idioma y conoces además todos los dialectos, que cambian constantemente, al igual que se transforman las vivencias de quienes los practican. Pero, además, hay que mirar por dentro de la materia tangible para encontrar las claves que conectan el compás con el corazón y la razón con nuestra 
realidad. La escena debe tener compás y, necesariamente, tiene que casar entre sí para que el arco argumental se sienta en armonía.

El flamenco, como vehículo comunicador de emociones, necesita un hábitat adecuado como el buen vino, la temperatura perfecta, el tiempo adecuado de fermentación en barrica, la uva que haya bebido del sustrato de la tierra. Los flamencos beben y viven de todo eso, y, a la hora de comunicar sus necesidades artísticas en sus obras escénicas, es muy común encontrar como necesidad narrativa sus propias vivencias como punto de partida para acceder a un buen guion. Es por esa razón que el fundamento para componer una buena pieza escénica para flamenco narrativo sale de convivir y conocer en profundidad su verdad, por oscura y dolorosa que sea. Los grandes artistas son grandes, no por lo virtuosos que puedan llegar a ser, sino por lo valientes que son a la hora de no guardar nada en el tintero y desnudarse sin pudor, llegando así al fondo de todo conflicto para poder sanar el alma a través del arte.

Yo acompaño al artista durante todo ese proceso, empujándolo en algunos casos a precipicios emocionales para ir descubriendo quiénes son realmente y desde qué prisma necesitan contar sus propias historias. Ese proceso puede llevar tiempo y, por ello, hay que dejar madurar lo descubierto para ver si realmente es sostenible para ser contado dentro del arco argumental. La cuestión en este caso, cuando hablamos de flamenco narrativo, no radica en ser totalmente explícito en lo que quieres decir, sino en dejar una puerta abierta al espectador para que pueda empatizar desde su propia vivencia lo que el intérprete está narrando y que nazca el vínculo entre ambos.
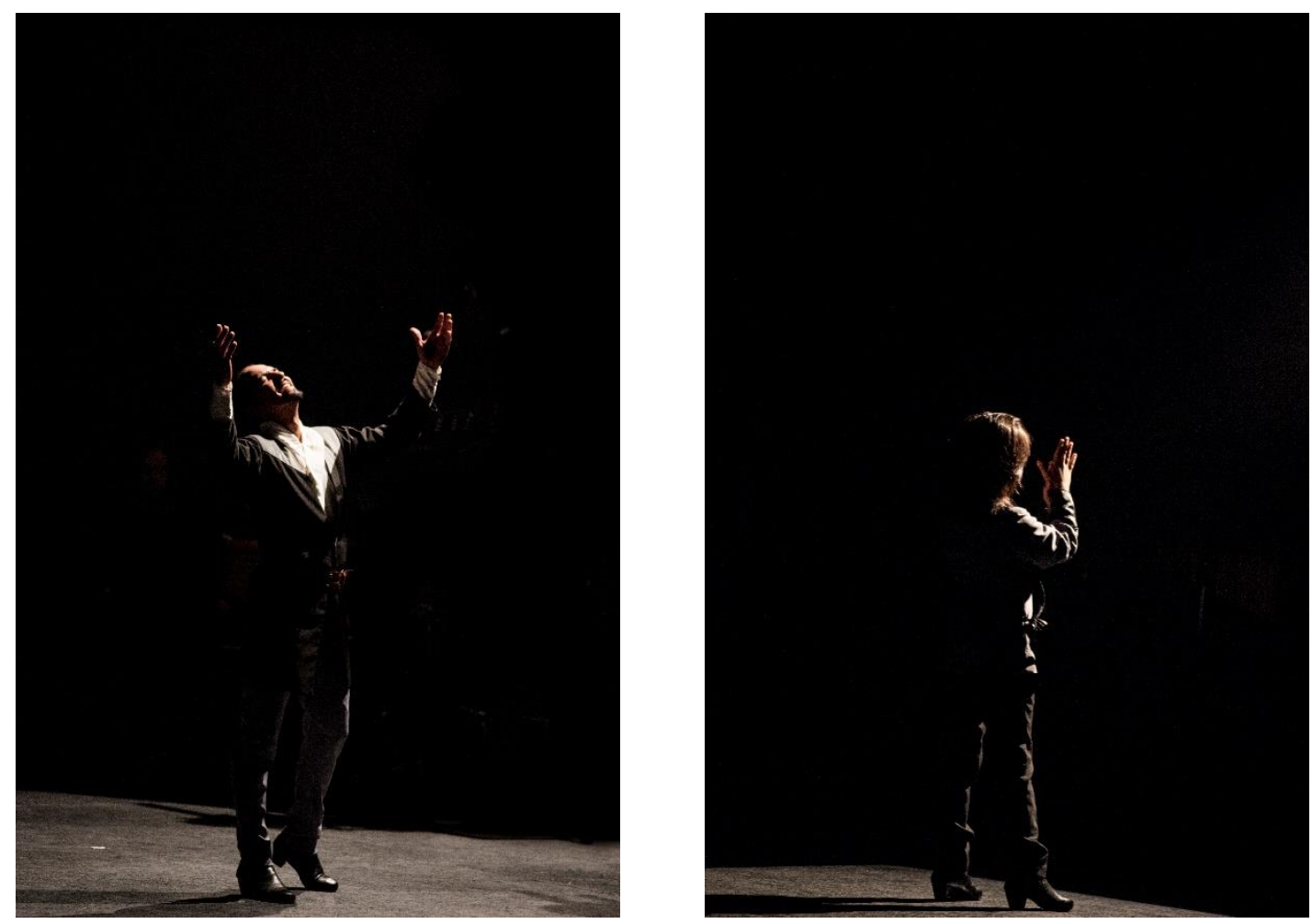

Imagen 3. Dos instantáneas de Farruquito y su hijo, El Moreno. Desde mi ventana, Bienal de Flamenco, Sevilla, 2020. Fotografía: Claudia Ruiz Claro.

Para que se pueda entender mejor este concepto, lo más adecuado es citar a uno de los creadores contemporáneos más relevantes dentro de la danza teatro europea: el sueco Mats Ek. Cuando 
analizamos sus obras narrativas con argumento libre - como la coreografía Niños viejos, estrenada en Estocolmo en 1989 por el Cullberg Ballet-, entendemos la narrativa de un argumento en movimiento, donde el público puede entender diferentes relaciones entre los personajes con diferentes interpretaciones sobre su desenlace. El secreto de todo ello radica en la «magia», por utilizar un término no académico, pero compartido por la comunidad flamenca, que encierra la libertad que nos brinda la danza, sin la utilización de la palabra.

Este imaginario creativo (donde el movimiento siempre marca lo narrativo y las conclusiones las tiene el espectador) es lo que, de forma permanente, utilizo como herramienta dentro de todas mis obras creadas para el flamenco, consiguiendo que el flamenco se exprese de forma libre y utilizando sus cantes, no como narradores literales, sino como narradores de emoción.

\section{La experiencia}

Cuando crucé la cancela de «Villa Alegría», la residencia de Farruquito, empecé el camino que me conduciría al ser humano para llegar al centro de los pilares que sostendrían el arco argumental de Desde mi ventana. Previamente, ya había tenido varios encuentros con las personas más cercanas a Farruquito, para ir descubriendo los diferentes puntos de vista que me darían los miembros de la saga de los Farrucos. La matriarca, el hermano, su esposa, sus hijos... Todos estos encuentros fueron trazando el mapa para poder emprender el viaje que me conduciría a Juan Fernández Montoya.

Para mí, este es el momento más emocionante de todo el proceso, cuando comienza el cuerpo a cuerpo, donde el director deja la jerarquía a un lado para comenzar desde lo personal a ser uno más, compartiendo quiénes y cómo son cada uno de los elementos a descubrir, donde desaparecen las fachadas infranqueables. Todo y todos al mismo nivel, en el mismo lugar.

Son muchos los prejuicios que, de un modo u otro, se tienen, aun cuando te crees que eso no va contigo por el hecho de ser creador. Hay muchos estigmas que te predisponen a actuar de un modo concreto. En este proceso de descubrimiento de quién era Juan, fui despojándome de todas las ideas con las que uno convive a través de los escaparates por donde vemos al resto de seres humanos y, en este caso concreto, a un artista icónico, pero a su vez controvertido, por lo que entraña ser el patriarca de la saga del baile más relevante de nuestra historia reciente.

Comenzamos a caminar juntos por sus recuerdos, centrándonos en el pasado y el presente... sin hacerle demasiado caso al futuro, para no perder la referencia y el pálpito de lo verdaderamente importante. El camino me tenía preparados grandes descubrimientos en torno a un buen puchero de potaje y largas conversaciones en su estudio de grabación, junto a una de sus principales pasiones en la vida: la música, solo interrumpidas por su ángel de la guarda, Rosario, que, más que su compañera, es su doble alma encarnada en cuerpo de mujer. Y por sus tres criaturas, que deseaban entrar y conocer al extraño que por esos días absorbía el tiempo de su padre en «Villa Alegría». 
Enclaves. Revista de Literatura, Música y Artes Escénicas, n.o 1, 2021, pp. 144-155. e-ISSN 2792-7350

Ángel Rojas, «La dirección artística en el flamenco. Experiencias Desde mi ventana»,

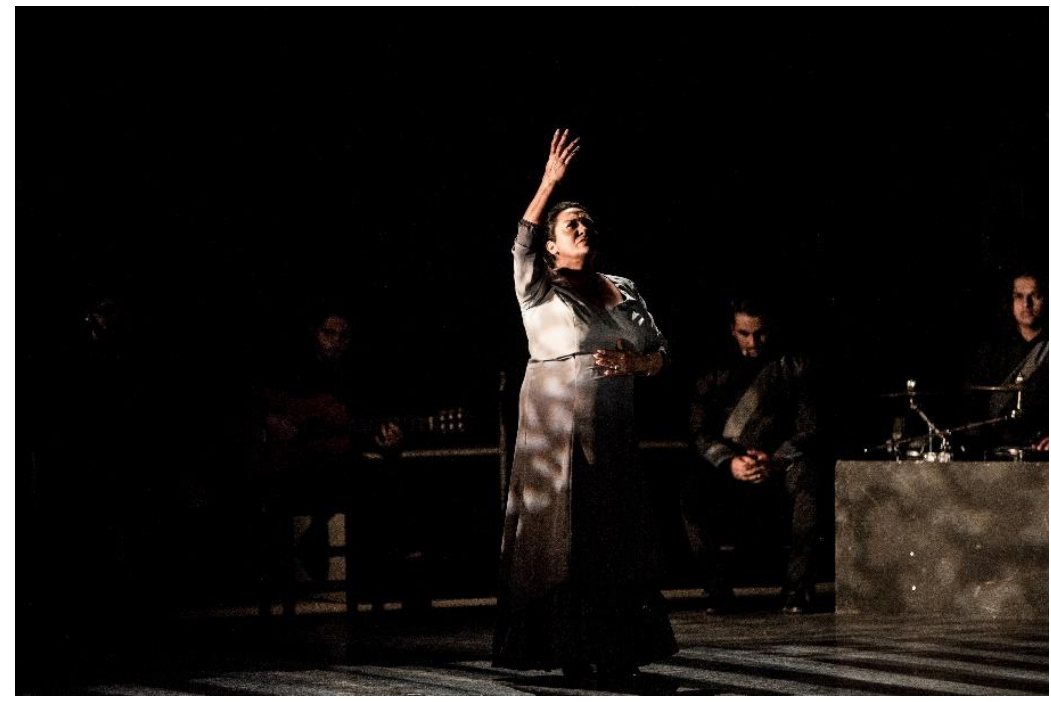

Imagen 4. La Farruca. Desde mi ventana, Bienal de Flamenco, Sevilla, 2020. Fotografía: Claudia Ruiz Claro.

Encontré en sus ojos los tesoros escondidos, porque Juan guarda su mayor tesoro dentro de los ojos de sus hijos. Salió el padre y mostró la necesidad de ser posible y convivir con el artista. Ahondamos en su infancia llena de recuerdos al lado del abuelo Farruco y me mostró generosamente su faceta de hijo y la admiración rotunda hacia su padre, el cantaor El Moreno. Pasamos por oscuros momentos y hasta quise rebobinar el tiempo para corregir los errores, pero fue Juan el que me dijo que lo vivido, aprendido está.

\section{La maduración}

Trascurrido este tiempo de descubrimiento mutuo, dejamos de vernos y yo volví a recluirme en el campo, el mismo lugar donde Farruquito me llamó para ofrecerme dirigir esta creación. Elegí como única compañía los recuerdos que Juan me había confiado, deseando poder encontrar las luces que nos hiciesen seguir caminando.

Juan es un ser de luz, alguien que tiene su propia energía, que alimenta al artista desde la calma y el sosiego aparente, pero realmente es esto mismo el verdadero motor que impulsa a Farruquito y lo hace ser único, dentro y fuera del escenario.

\section{PATRIARCADO}

MIEDO

RESPONSABILIDAD

ARTE

MUERTE

GLORIA

PADRE

DOLOR

LUZ

FRUSTRACIÓN 
Todas estas palabras comenzaron a amontonarse desordenadamente en mi cabeza, pidiendo ser escuchadas y, sobre todo, ser ordenadas para mostrarse útiles y contar así la historia de manera honesta. ¿Qué pesaba más, el artista, la persona, el dolor o la luz...? Lo teníamos todo delante de nosotros, y estaba en el momento justo para comenzar a organizar el puzle.

Cuando se trata de acariciar los recuerdos de grandes artistas para ayudarles a contar sus verdades, no existen método aprendido ni reglas iguales. Solo lanzarse a escuchar el pálpito y no temer a la hora de mirar en el fondo de todo para conseguir ser el nexo de unión entre lo que somos y lo que quisiéramos ser. Juan me dejó un deseo entre tantos recuerdos, algo que marcaría mi búsqueda y sobre todo mi misión. Quería que Desde mi ventana fuese un «agradecimiento a la vida». Esto me marcó de un modo especial. En el flamenco, se tiende a contar la parte oscura y dolorosa del intérprete, la soleá, como refugio y talismán. Pero él me encargó todo lo contrario: que prevaleciese sobre la oscuridad la luz que — paradojas de la vida - él había ido construyendo desde sus dolorosas vivencias. Era el mejor deseo y realmente fue esto lo que me ayudó a encontrar códigos y rincones diferentes para crear una pieza a la medida de Juan - contemplando y representando al hombre - y a la altura de Farruquito, permitiendo que el bailaor pudiera exponer todo su conocimiento y toda su personalidad artística en el escenario.

Esa luz que yo traducía en salvavidas la tuve delante de mí durante el tiempo que pasé en «Villa Alegría», y no estaba en otro lugar que en los ojos de sus tres criaturas. Por esa razón, lo primero que puse encima de la mesa a la hora de construir el guion fue eso: cómo transformar ese pensamiento en escena teatral.

La ventana era, alegóricamente, el elemento para contar todas esas emociones que me encontré en «Villa Alegría». Una ventana que nos permitiese ver quién era Juan en su intimidad, con dos versos internos en las imágenes: lo que era real y lo que salía de sus pensamientos.

El elemento audiovisual apareció de inmediato en mi cabeza, a pesar de que yo no soy muy admirador de este recurso dentro de mi universo creativo. ¿Cómo integrarlo de manera sutil pero rotunda en los diferentes pasajes que la obra necesitaba? El color de las imágenes no salía por ningún pensamiento; solo aparecía el blanco y el negro, como si el color nos quisiese dar la cara y la cruz de las verdades de Juan. 

https://dx.doi.org/10.12795/enclaves.2021.101.09

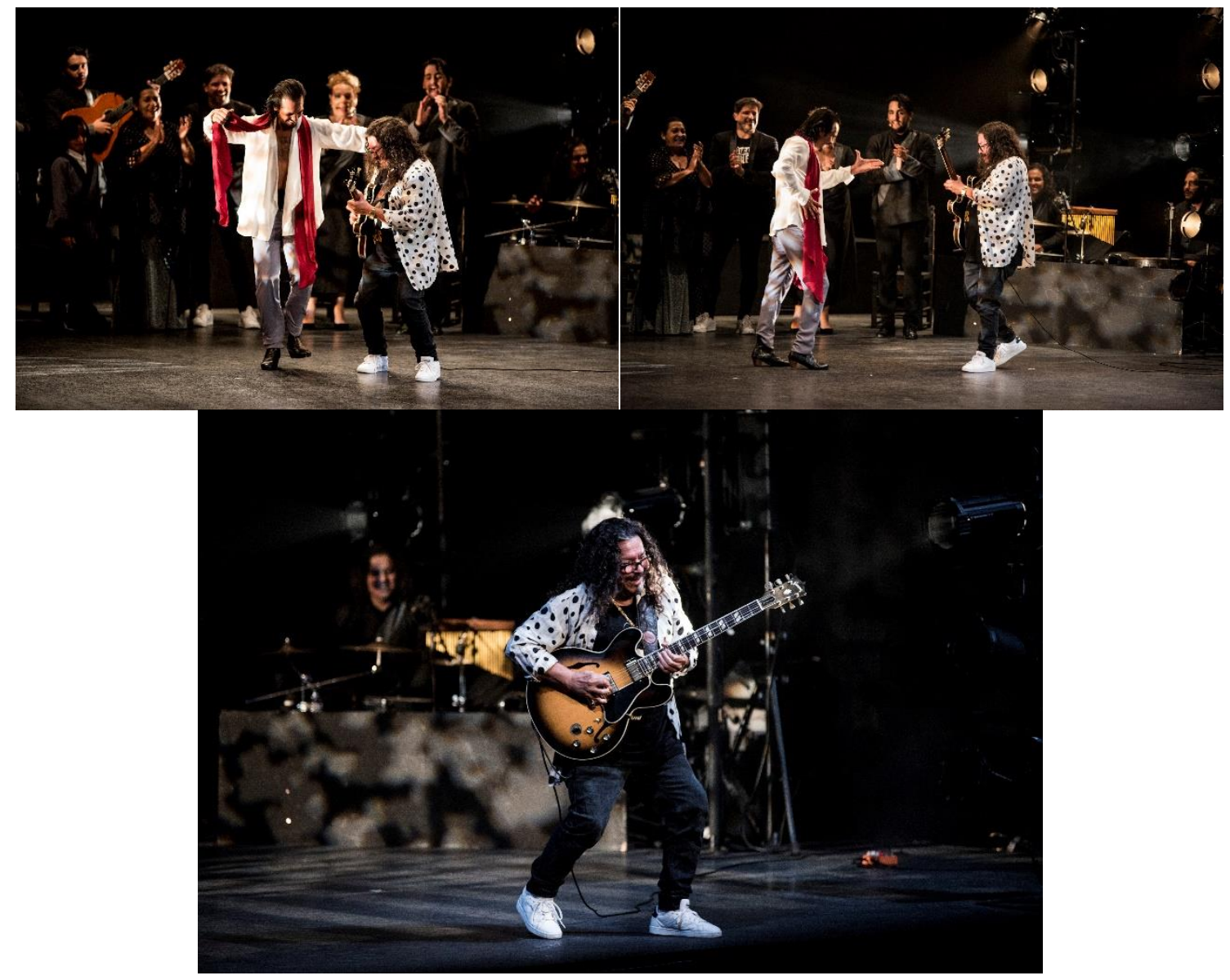

Imagen 5. Colaboración de Raimundo Amador en Desde mi ventana, Bienal de Flamenco, Sevilla, 2020. Fotografía: Claudia Ruiz Claro.

Y, de nuevo, los ojos de sus hijos, que pedían aparecer en esa ventana de dimensiones teatrales situada a la izquierda de la escena, desplazando el centro del escenario para buscar nuevos caminos, nuevos ángulos; creando un escenario paralelo a su ventana para que Farruquito conviviera con Juan.

A pesar de que los métodos para abordar los procesos creativos normalmente no se parecen entre sí, hay un elemento que de forma permanente se repite en mi forma de concebir las obras. Es lo que marca el orden entre tanto caos creativo. Construir la casa para luego habitarla. Es un acto necesario para poder sentirte «en control» entre tanto aparente desorden. Necesito crear el espacio escénico para que, seguidamente, aparezcan la luz, el ángulo y la dirección de los focos, porque la luz en la danza y en particular en el flamenco es el actor que baila con los bailaores, un elemento fundamental para crear las escenográficas en movimiento. Sentía que debía crear paralelamente al espacio escénico y el guion, la luz que lo envolvería todo. Y de nuevo no aparecía el color... Parecía que estuviese pidiendo la carne viva del foco sin filtrar, la crudeza y la verdad asociadas a los recuerdos para transformarse en luz y alabanza que agradeciese lo aprendido en el camino.

El espacio escénico que se vislumbraba no era un espacio convencional aforado a la italiana. Necesitaba sacar las torres de luces y que ocupasen un lugar protagonista en el escenario, como si quisieran contar lo que estaba por venir tras esa ventana. Y, de nuevo, la tripa del teatro a la vista, con los aparatos como elementos tangibles. 
Enclaves. Revista de Literatura, Música y Artes Escénicas, n. ${ }^{\circ}$ 1, 2021, pp. 144-155. e-ISSN 2792-7350

Ángel Rojas, «La dirección artística en el flamenco. Experiencias Desde mi ventana», https://dx.doi.org/10.12795/enclaves.2021.101.09

La propuesta de espacio escénico e iluminación que se presentaban ante mí era un reto para los márgenes donde se solía mover Farruquito, teniendo en cuenta su recorrido como bailaor tradicional. De modo que una de mis principales preguntas fue hasta dónde podía exponer a Farruquito para que fuese un lugar ajeno, pero a su vez sostenible.

Uno de los grandes aprendizajes que he tenido durante este proceso de dirección artística ha sido conocer el límite que los intérpretes están dispuestos a sostener. En mi caso, y basando mis creaciones en un marco amplio de conocimientos y experiencias, resulta por momentos contradictorio asumir que tu límite no es siempre el límite del resto del elenco. Si no respetas eso y fuerzas la máquina algo más de lo soportable, el intérprete no será capaz de defender la propuesta y el fracaso será, sin lugar a dudas, responsabilidad del director. Cada experiencia dirigiendo es para mí una lección de vida. Por esa razón, tuve claro que Farruquito estaría dando un gran salto en lo escénico, pero no debía tocar nada más de sus pilares si no quería llevar la creación al precipicio. El baile y la música debían ser los pilares donde Juan y Farruquito estuvieran dentro de su zona de confort.

Recibí la partitura ya completa, a falta de ser entregada a los músicos. Juan tenía una estructura musical muy sólida basada en sus propias composiciones, y algo muy importante: las letras también compuestas por él le daban al argumento una coherencia que sirvió de guía para construir el guion de la obra.

«De la luz hasta la luz», esa era la verdadera idea fuerza, transitando inevitablemente por toda una vida dedicada a aprender a caminar por lares no siempre cómodos y confortables.

Faltaba algo importante para terminar de construir el nuevo mundo donde descubrir a un Farruquito diferente. La línea estética del vestuario. Un imaginario lleno de connotaciones que iban de forma directa a un mundo que no tenía relación con el flamenco, pero que, al descubrir la personalidad de Juan, se mostraba inevitable. No podía contarse de otro modo.

Apoyándome en el ser humano y en su fortaleza, me acerqué al imaginario de los guerreros samuráis y los emperadores japoneses. La fortaleza de Juan es de una envergadura indescriptible. Solo las personas con la entereza de Juan salen reforzadas tras vivir experiencias de pérdida llevadas al extremo; no solo la pérdida de los seres queridos, sino — y aquí erradica la complejidad - la pérdida de libertad. Por esa razón, y tras conectar de manera directa con el ser humano, no podía dejar de ver a Juan como un guerrero de fortalezas infinitas. A él y, por ende, a todo el resto del elenco artístico que le acompañarían durante este viaje escénico.

Escuchar y ordenar era mi labor en esos días de retiro en el campo, y estar atento a todas las necesidades que iban apareciendo y pidiendo paso para ser colocadas y entendidas.

El guion avanzaba y clarificaba todos sus recuerdos, situándolos en un espacio escénico que estaba cada vez más claro, donde tanto la luz como la estética conectaban directamente con la verdad que se me había confiado para construir el viaje. Por fin llegó el momento de trasladar todo lo encontrado a las manos, los pies y los corazones de la compañía liderada por quien, para muchos aficionados flamencos, es el «Capitán de Capitanes».

\section{La obra}

De vuelta a Sevilla, comenzaron los ensayos con toda la compañía. Llegaba el momento de convencer a los flamencos, tarea compleja si no eres miembro directo del clan. Pero como apoyo fundamental estaba Farruquito, quien me avaló como parte clave para llevar ese barco al mejor puerto.

La relación que existía entre lo escrito en un guion y lo real comenzaba a tener un diálogo común, y de una manera natural, ambos caminaban en la misma dirección. Los intérpretes sentían la libertad de expresarse dentro de las indicaciones que yo les iba marcando, y 
Enclaves. Revista de Literatura, Música y Artes Escénicas, n. ${ }^{\circ}$ 1, 2021, pp. 144-155. e-ISSN 2792-7350

Ángel Rojas, «La dirección artística en el flamenco. Experiencias Desde mi ventana», https://dx.doi.org/10.12795/enclaves.2021.i01.09

Farruquito se sentía cómodo en los nuevos códigos que, desde la propuesta artística, le había planteado.

Los cantes tenían que convivir ahora con el movimiento escénico. Naturalizar una caminada a la vez que se interpreta una malagueña no siempre es sencillo, porque hay que disociar la respiración que el cante te pide y el tempo del movimiento. Dos sentidos en un solo cuerpo.

Las escenas se iban construyendo dentro de una armonía poco habitual tratándose de un montaje de esta envergadura, como la velocidad y la calma exactas, entrelazando la juventud y la veteranía de un elenco que respetaba al cien por cien mis indicaciones. Parecían actores entrenados para ser intérpretes, más que artistas flamencos.

Gran parte del éxito se debió a que me encontré con un elenco al más alto nivel de excelencia flamenca pero, además, con una disciplina encomiable. El respeto y admiración a Juan fueron motivos principales para que se diesen esos mimbres. El trabajo con todos ellos fue, como se suele decir, un «camino de rosas». Ello, conjugado con la excelencia artística, hizo que Desde mi ventana se convirtiese en el mejor espectáculo de Farruquito hasta la fecha, según la exigente crítica sevillana, y uno de los espectáculos triunfadores de la pasada Bienal.

Cuando estrenas una creación, cuando llega el momento de levantar el telón, la función ya no te pertenece. Es entonces cuando el director - al menos en mi caso - siente que está «en caída libre» y, realmente, no sabe si el paracaídas se abrirá en el momento adecuado. En ese momento, el director es el elemento más vulnerable de todo este gran engranaje. Ya no puedes hacer nada, ya no está en tu mano proteger más al elenco. Es el momento en el que te preguntas si has llevado tu trabajo al límite para conseguir que la máxima figura del baile flamenco de nuestro tiempo lograse el esperado camino de rumbo en su carrera, siendo este el principal motivo para el que yo había sido llamado. En ese momento, justo antes de levantar el telón, con toda la crème sevillana sentada en la bombonera de Sevilla, el mítico y querido Teatro Lope de Vega, todo se tambalea y las dudas se apoderan del pensamiento.

Pero cuando compartes una experiencia con la verdad de quien sabe enfrentarse a sí mismo del modo en el que Juan lo hizo, al levantar el telón y comenzar el primer audiovisual, lo que más arriba hemos calificado como «magia» se hizo espectáculo y el poder del teatro se hizo flamenco. La conjunción de todos los elementos rodaba, como si hubieran estado esperando a ser llamados juntos hacia una eternidad, y la masa rugió cuando sonaron los primeros compases en los nudillos de Farruquito, dejando atrás a Juan en la gran «ventana» desde donde se muestra la materia viva del ser humano que encierra este grande del baile.

Son muchas las conclusiones a las que se puede llegar al final de un viaje de este nivel artístico pero, si me tuviese que quedar con una sola, sería la maravilla de conjugar la vida y el arte a través de un mismo sentir, que es lo que el flamenco nos regala. Poder sanar la vida con el arte, abrazando a los seres humanos, siempre a compás.

Desde mi ventana se estrenó en el Teatro Lope de Vega de Sevilla, en el marco de la Bienal de Flamenco, el 9 de septiembre de 2020. 


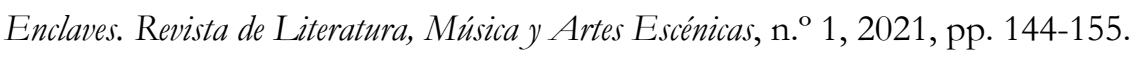
e-ISSN 2792-7350

Ángel Rojas, «La dirección artística en el flamenco. Experiencias Desde mi ventana», https://dx.doi.org/10.12795/enclaves.2021.i01.09

\section{9:nclaves}

Revista de Literatura, Música y Artes Escénicas

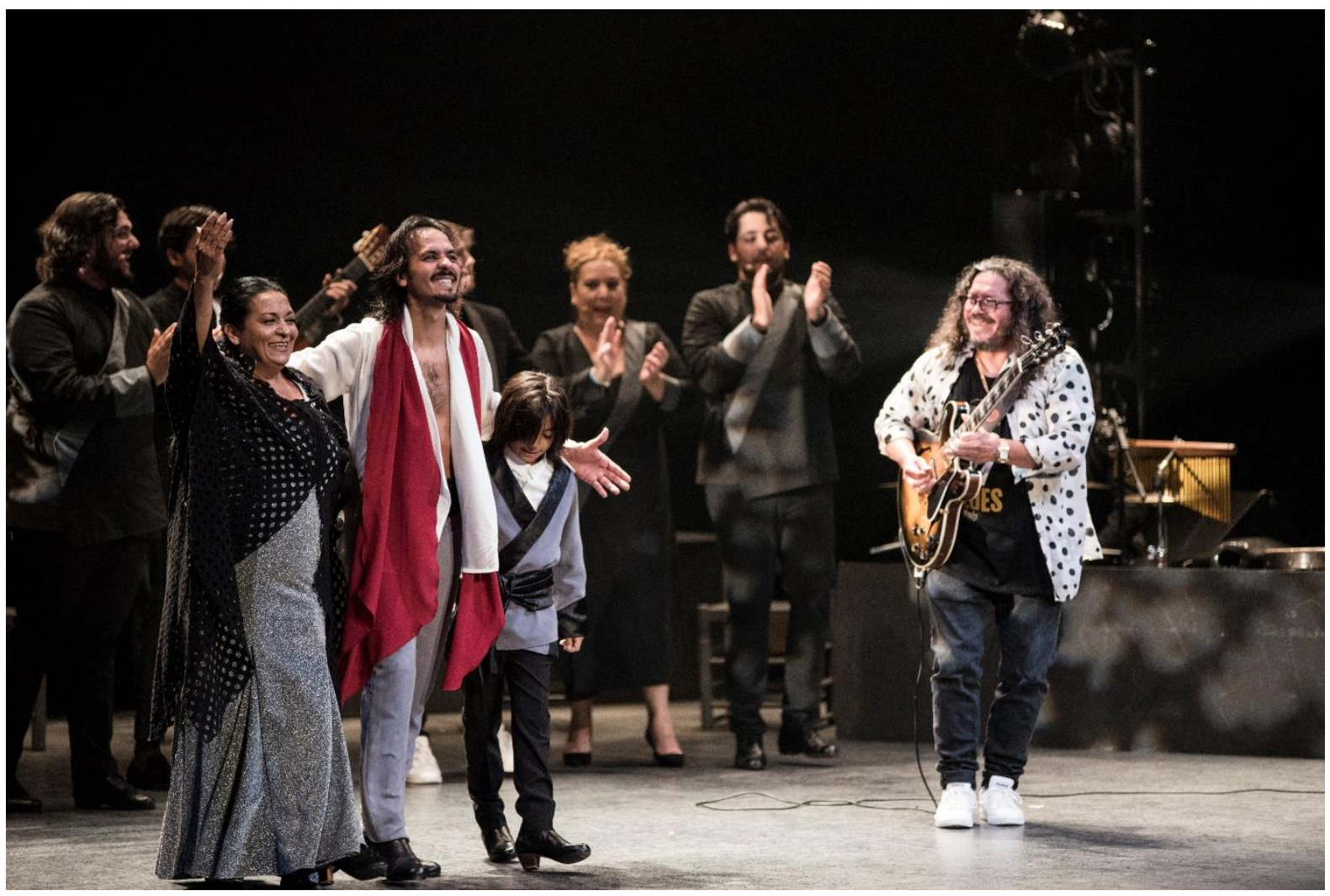

Imagen 6. Saludo de cierre. Desde mi ventana, Bienal de Flamenco, Sevilla, 2020. Fotografía: Claudia Ruiz Claro. 